\title{
ESTUDO DE CASO: ANÁLISE DE UM RELATÓRIO DE CONTROLE AMBIENTAL (RCA) REFERENTE À ATIVIDADE DE LEVANTAMENTO SÍSMICO
}

\section{IGOR LEONARDO DE MORAIS NASCIMENTO}

moraisnascimento@yahoo.com.br

Pós-graduando em Licenciamento ambiental on shore - IFRN

LECI MARTINS MENEZES REIS

Profa. do IFRN

leci@cefetrn.br

\begin{abstract}
RESUMO
Este trabalho aborda a análise de um Relatório de Controle Ambiental (RCA), da atividade de sísmica, submetido à obtenção de licenciamento ambiental junto ao Instituto de Defesa do Meio Ambiente - IDEMA. Realiza uma comparação dos itens exigidos no Termo de Referência (TR) do IDEMA com o Estudo ambiental citado, a fim de identificar se todos os itens exigidos legalmente foram contemplados no RCA e se os mesmos estão em conformidade com o Termo. Utiliza a técnica de estudo de impacto ambiental baseado em um contexto legal que estabelece requisitos a serem observados e procedimentos a serem cumpridos, tal técnica é a análise formal da qualidade de um estudo ambiental. Verifica, também, a repetição ou não das principais deficiências apontadas no elemento Mitigação e compensação de impactos com base no estudo do Ministério Público Federal - MPF, a partir da técnica de análise de conteúdo de estudo ambiental.
\end{abstract}

PALAVRAS-CHAVE: Relatório de Controle Ambiental. Estudo Ambiental. Licenciamento Ambiental.

\begin{abstract}
This paper aims to analysis of a report of environmental control (REC), of the sismic activity, submited to obtain the environmental license from Instituto de Defesa do Meio Ambiente - IDEMA. It compares the required items in the Reference Term (RT) of IDEMA with cited environmental study. In order to identify if all legal required items were achieved in the REC and if they are the way the Term states. It uses the study technique of environmental impact based on a legal context that estabilishes requirements to be observed and procedures to be done, such technique is the formal analysis of an environmental study's quality. It also verifies whether there's repetition of the main deficiencies pointed in the element Mitigation and compensation of impacts based on the study made by Ministério Público Federal - MPF, from the technique of analysis of the environmental study's content.
\end{abstract}

KEY-WORDS: Report of Environmental Control. Environmental Study. Environmental License. 


\section{ESTUDO DE CASO: ANÁLISE DE UM RELATÓRIO DE CONTROLE AMBIENTAL (RCA) REFERENTE À ATIVIDADE DE LEVANTAMENTO SÍSMICO}

\section{INTRODUÇÃO}

É assegurado pela Constituição Federal de 1988 em seu art. 225 o direito a todos ao meio ambiente ecologicamente equilibrado, que seja bem comum do povo e essencial a qualidade de vida. No mesmo artigo, exige-se do poder público e da coletividade o dever de defender e preservar o meio ambiente para as presentes e futuras gerações. Ainda em seu parágrafo primeiro e em conjunto com o inciso IV do mesmo artigo, foi incumbido ao poder público para assegurar a efetividade desse direito a exigência, na forma da lei, para instalação de obra ou atividade potencialmente causadora de significativa degradação do meio ambiente, estudo prévio de impacto ambiental, o qual se deve dá publicidade.

Com o exposto acima, podemos verificar que os estudos ambientais assumem uma grande importância no que tange a preservação ambiental. No entanto, apenas o estudo em si não garante o nosso direito a um meio ambiente ecologicamente equilibrado, é necessário que tenhamos estudos ambientais de qualidade, dotados de informações que subsidiem o processo de licenciamento ambiental dos órgãos ambientais. Dessa forma a qualidade do estudo ambiental torna-se um fator determinante para que tenhamos empreendimentos ecologicamente adequados.

Mais do que isso, é necessário que os estudos sejam analisados e criticados por todas as partes envolvidas nesse processo (SÁNCHEZ, 2006), tais como: Empresas que contratam estudos de impacto ambiental podem analisá-los antes de submetê-los à aprovação dos órgãos governamentais ou de agentes financeiros; Associações que representam o público como organizações não governamentais e associações de moradores, podem analisar os estudos para buscar um melhor entendimento do projeto e de suas conseqüências; no caso de posturas contrárias ao empreendimento, a análise pode apontar falhas e lacunas que podem ser apresentadas como argumentos no debate; ela pode também indicar deficiências do projeto ou apontar para alternativas não estudadas, ou ainda sugerir novas medidas mitigadoras ou compensatórias, não consideradas no estudo; Membros do Ministério Público, assistentes técnicos e peritos judiciais, no caso de disputas judiciais envolvendo atividades sujeitas ao processo de avaliação de impacto ambiental; Agências setoriais reguladoras e outros órgãos governamentais interessados no empreendimento apresentado; Agentes financiadores públicos ou privados, cuja política inclua a discussão da viabilidade ambiental dos empreendimentos que lhes são submetidos; Órgãos governamentais com atribuições específicas, que devem ser ouvidos no licenciamento de uma atividade.

A relevância do tema proposto neste estudo de caso consiste no fato de expor que a realidade dos estudos ambientais postos aos órgãos ambientais para o licenciamento ambiental não condiz com os conceitos teóricos estudados no curso de licenciamento ambiental on shore. A escassez de produção cientifica que aborde tal assunto, também deve ser utilizada como justificativa para esse trabalho, pretendendo-se que o produto final resultante do mesmo ultrapasse a esfera acadêmica e contribua na reavaliação das atuais práticas de licenciamento ambiental on shore. Sendo esse último, o principal motivo do estudo a seguir.

\section{REFERÊNCIAL TEÓRICO}


Geralmente, os estudos de impactos ambientais são realizados dentro de um contexto legal, no qual é feita uma comparação entre os pontos abordados, no estudo em questão, e os requisitos determinados pelo Termo de Referência (TR). Contudo, esse não é o único método. Tal estudo pode ser feito baseado numa prática recomendada, internacionalmente reconhecida, ou ainda seguindo recomendações de organismos internacionais ou órgão federais competentes.

Independentemente do método utilizado, tal estudo deve garantir ao analista o atendimento aos requisitos mínimos estabelecidos pela regulamentação aplicável, assim como, apresentar qualidade técnica suficiente para subsidiar a tomada de decisões sobre o empreendimento. Em outras palavras, busca-se determinar se o estudo de impacto tem forma e conteúdo satisfatórios e adequados para a aprovação da concessão da licença ambiental.

Se o estudo ambiental atende aos requisitos preestabelecidos, afirmamos que o mesmo apresenta a qualidade "formal”. Atendendo a critérios técnicos relevantes, afirmamos que este apresenta a qualidade “de conteúdo”. Normalmente este último está baseado nas melhores práticas adotadas internacionalmente (best practice). Vale salientar que a qualidade formal e a de conteúdo não são excludentes e tanto podem, como devem, ser complementares.

De acordo com Lee (2000, p. 138), um bom estudo ambiental: "é aquele que apresenta, de uma forma apropriada para os usuários, constatações e conclusões que cubram todas as tarefas da avaliação, empregando métodos apropriados de coleta de informação, análise e comunicação". No Brasil, o conteúdo mínimo exigido em um estudo de impacto ambiental é determinado pela Resolução de $n^{0} 1$ de 1986 do Conselho Nacional do Meio Ambiente CONAMA, porém os órgãos licenciadores estaduais podem ter seus próprios critérios, desde que não sejam menos restritivos que aqueles estabelecidos pela norma federal e não a contrarie. Portanto, um estudo que não apresente o conteúdo mínimo exigido não deve ser aceito pelo órgão ambiental. Contudo, é desejável que o estudo apresente o atendimento aos requisitos legais e as práticas mundialmente reconhecidas.

Com base nesse entendimento, o estudo de caso a seguir, não procura se limitar à verificação do atendimento aos requisitos mínimos estabelecidos pela lei, apesar das restrições de tempo e da complexidade e riqueza da abordagem da técnica de avaliação da qualidade de conteúdo, a mesma também será trabalhada.

O trabalho a seguir tem como referência, o Termo de Referência do Instituto de Defesa do Meio Ambiente - IDEMA e um estudo feito em 2004 por uma equipe de analistas do Ministério Público Federal - MPF, em uma população de oitenta EIA's Brasileiros de projetos postos ao licenciamento ambiental federal ou que implicaram, por diversas razões, no envolvimento do Ministério Público Federal. Como resultado do trabalho do MPF, temse o Quadro 1 que identifica todos os elementos do EIA, assim como as suas principais deficiências. Dessa forma, o estudo de caso proposto visa verificar a conformidade com o TR e a ocorrência ou não das principais deficiências apontadas pelo Quadro 1, no que tange ao elemento de Mitigação e Compensação de impactos, já que o mesmo pode ser considerado uma boa prática recomendada. 
Quadro 1 - Deficiências em estudos de impacto ambiental no Brasil

\begin{tabular}{|c|c|}
\hline Elemento do EIA & Principais Deficiências \\
\hline $\begin{array}{l}\text { Estudo de } \\
\text { alternativas }\end{array}$ & $\begin{array}{l}\text { Ausência de proposição de alternativas; } \\
\text { Apresentação de alternativas reconhecidamente inferiores à } \\
\text { selecionada no EIA; } \\
\text { Prevalência dos aspectos econômicos sobre os ambientais na escolha } \\
\text { de Alternativas; } \\
\text { Comparação de alternativas a partir de base de conhecimento } \\
\text { diferenciada; }\end{array}$ \\
\hline $\begin{array}{l}\text { Delimitação das } \\
\text { áreas de influência }\end{array}$ & $\begin{array}{l}\text { Desconsideração da bacia hidrográfica; } \\
\text { Delimitação das áreas de influência sem alicerce nas características e } \\
\text { vulnerabilidades dos ambientes naturais e nas realidades sociais } \\
\text { regionais; }\end{array}$ \\
\hline & $\begin{array}{l}\text { Prazos insuficientes para a realização de pesquisas de campo; } \\
\text { Caracterização da área baseada, predominantemente, em dados } \\
\text { secundários; } \\
\text { Ausência ou insuficiência de informações sobre a metodologia } \\
\text { utilizada; } \\
\text { Proposição de execução de atividades de diagnóstico em etapas do } \\
\text { licenciamento posteriores à Licença Prévia; } \\
\text { Falta de integração dos dados de estudos específicos; }\end{array}$ \\
\hline $\begin{array}{l}\text { Diagnóstico } \\
\text { ambiental - } \\
\text { meios físico e } \\
\text { biótico }\end{array}$ & $\begin{array}{l}\text { Ausência de mapas temáticos; } \\
\text { Utilização de mapas em escala inadequada, desatualizados e/ou com } \\
\text { ausência de informações; } \\
\text { Ausência de dados que abarquem um ano hidrológico, no mínimo; } \\
\text { Apresentação de informações inexatas, imprecisas ou contraditórias; } \\
\text { Deficiências na amostragem para o diagnóstico; } \\
\text { Caracterização incompleta de águas, sedimentos, solos, resíduos, ar, } \\
\text { etc; } \\
\text { Desconsideração da interdependência entre precipitação e } \\
\text { escoamento superficial e subterrâneo; } \\
\text { Superficialidade ou ausência de análise de eventos singulares em } \\
\text { projetos envolvendo recursos hídricos; } \\
\text { Ausência ou insuficiência de dados quantitativos sobre a vegetação; } \\
\text { Ausência de dados sobre organismos de determinados grupos ou } \\
\text { categorias; } \\
\text { Ausência de diagnóstico de sítios de reprodução (criadouros) e } \\
\text { alimentação de animais; }\end{array}$ \\
\hline $\begin{array}{l}\text { Diagnóstico } \\
\text { ambiental - } \\
\text { meio antrópico }\end{array}$ & $\begin{array}{l}\text { Pesquisas insuficientes e metodologicamente ineficazes; } \\
\text { Conhecimento insatisfatório dos modos de vida de coletividades } \\
\text { socioculturais singulares e suas redes intercomunitárias; } \\
\text { Ausência de estudos orientados pela ampla acepção do conceito de } \\
\text { patrimônio cultural; } \\
\text { Não-adoção de uma abordagem urbanística integrada em } \\
\text { diagnósticos de áreas e populações urbanas afetadas; } \\
\text { Caracterizações socioeconômicas regionais genéricas, não articuladas }\end{array}$ \\
\hline
\end{tabular}




\begin{tabular}{|c|c|}
\hline & às pesquisas diretas locais; \\
\hline $\begin{array}{l}\text { Identificação, } \\
\text { caracterização } \\
\text { e análise dos } \\
\text { impactos }\end{array}$ & $\begin{array}{l}\text { Não-identificação de determinados impactos (omissões em termos de } \\
\text { impactos passíveis de previsão, impactos negativos indiretos sequer } \\
\text { mecionados); } \\
\text { Identificação parcial de impactos; } \\
\text { Identificação de impactos genéricos (por vezes são tantos os } \\
\text { impactos agrupados sob um único titulo que sua importância e } \\
\text { significado não podem ser estabelecidos satisfatoriamente; } \\
\text { Identificação de impactos mutuamente excludentes; } \\
\text { Subutilização ou desconsideração de dados dos diagnósticos; } \\
\text { Omissão de dados e/ou de justificativas quanto à metodologia } \\
\text { utilizada para atribuir pesos aos atributos dos impactos; }\end{array}$ \\
\hline $\begin{array}{l}\text { Cumulatividade e } \\
\text { sinergia de } \\
\text { impactos }\end{array}$ & Aspectos desconsiderados; \\
\hline $\begin{array}{l}\text { Mitigação e } \\
\text { compensação } \\
\text { de impactos }\end{array}$ & $\begin{array}{l}\text { Proposição de medidas que não são a solução para a mitigação do } \\
\text { impacto; } \\
\text { Indicação de medidas mitigadoras pouco detalhadas; } \\
\text { Indicação de obrigações ou impedimentos, técnicos e legais, como } \\
\text { propostas de medidas mitigadoras; } \\
\text { Ausência de avaliação da eficiência das medidas mitigadoras } \\
\text { propostas; } \\
\text { Deslocamento compulsório de populações: propostas iniciais de } \\
\text { compensações de perdas baseadas em diagnósticos inadequados; } \\
\text { Não-incorporação de propostas dos grupos sociais afetados, na fase } \\
\text { de formulação do EIA; } \\
\text { Proposição de Unidade de Conservação da categoria de uso } \\
\text { sustentável para a aplicação dos recursos, em casos não previstos } \\
\text { pela legislação; }\end{array}$ \\
\hline $\begin{array}{l}\text { Programa de } \\
\text { monitoramento e } \\
\text { acompanhamento } \\
\text { ambiental }\end{array}$ & $\begin{array}{l}\text { Erros conceituais na indicação de monitoramento; } \\
\text { Ausência de proposição de programa de monitoramento de impactos } \\
\text { específicos; }\end{array}$ \\
\hline Rima & $\begin{array}{l}\text { O Rima é um documento incompleto; } \\
\text { Emprego de linguagem inadequada à compreensão do público. }\end{array}$ \\
\hline
\end{tabular}

Fonte: SÁNCHEZ (2006).

Sendo assim, foi tomado como referência os ditames teóricos e legais que fundamentam o estudo aqui referido, apresentados nos itens a seguir.

\subsection{O LICENCIAMENTO AMBIENTAL}

O licenciamento ambiental, de acordo com Lima (2006), se constitui num procedimento complexo que envolve análises técnicas e discussão pública das informações produzidas, que tem como objetivo guiar o órgão competente pelo licenciamento na tomada de decisão quanto à implementação de atividades ou obras efetiva ou potencialmente causadora de impactos ambientais. 
Outros atores como Fink et al. (2004), acrescentam ainda que o licenciamento não se limita a um simples ato, mas, sim, a uma série de passos encadeados com vistas à verificação de que certa atividade está dentro dos padrões ambientais permitidos.

Segundo a Resolução Conama 237/97 o licenciamento ambiental é um procedimento administrativo pelo qual o órgão ambiental competente licencia a localização, instalação, ampliação e a operação de empreendimentos e atividades utilizadoras de recursos ambientais, consideradas efetiva ou potencialmente poluidoras ou daquelas que, sob qualquer forma, possam causar degradação ambiental, considerando as disposições legais e regulamentares e as normas técnicas aplicáveis ao caso.

\subsubsection{Licença ambiental}

A Licença ambiental, segundo a Resolução CONAMA 237/97, é um ato administrativo pelo qual o órgão ambiental competente, estabelece as condições, restrições e medidas de controle ambiental que deverão ser obedecidas pelo empreendedor, pessoa física ou jurídica, para localizar, instalar, ampliar e operar empreendimentos ou atividades utilizadoras dos recursos ambientais consideradas efetiva ou potencialmente poluidoras ou aquelas que, sob qualquer forma, possam causar degradação ambiental (CONAMA, 1997).

O licenciamento ambiental, em linhas gerais, compreende 3 tipos de licença: a Licença Prévia - LP, a Licença de Instalação - LI e a Licença de Operação - LO.

\subsubsection{O Licenciamento ambiental on shore}

O licenciamento de atividades relacionadas à exploração e lavra de jazidas de combustíveis líquidos e gás natural, são estabelecidos de acordo com a Resolução CONAMA 23/94.

O licenciamento ambiental das atividades petrolíferas no mar (off shore), com base na localização do empreendimento e no alcance de seu impacto ambiental, cumpre ao IBAMA a competência de seu licenciamento de acordo com o art. $4^{\circ}$ da Resolução CONAMA 237/97. Por outro lado, o licenciamento das atividades de exploração e produção de petróleo em terra (on shore) compete aos órgãos estaduais de meio ambiente.

No Rio Grande do Norte, o licenciamento ambiental é baseado na Política Estadual do Meio Ambiente (PEMA) estabelecida na Lei Complementar Estadual $n^{\circ} 272$ de 03 de março de 2004 e pela Lei Complementar Estadual no 336 de 12 de dezembro de 2006.

Para a atividade petrolífera on shore, exigem-se as seguintes licenças: Licença Prévia para Perfuração (LPper), Licença Prévia de Produção para Pesquisa (LPpro), Licença de Instalação (LI) e Licença de Operação (LO), de acordo com a Lei Complementar $n^{\circ}$ 272/2004 (ver Figura 1). 


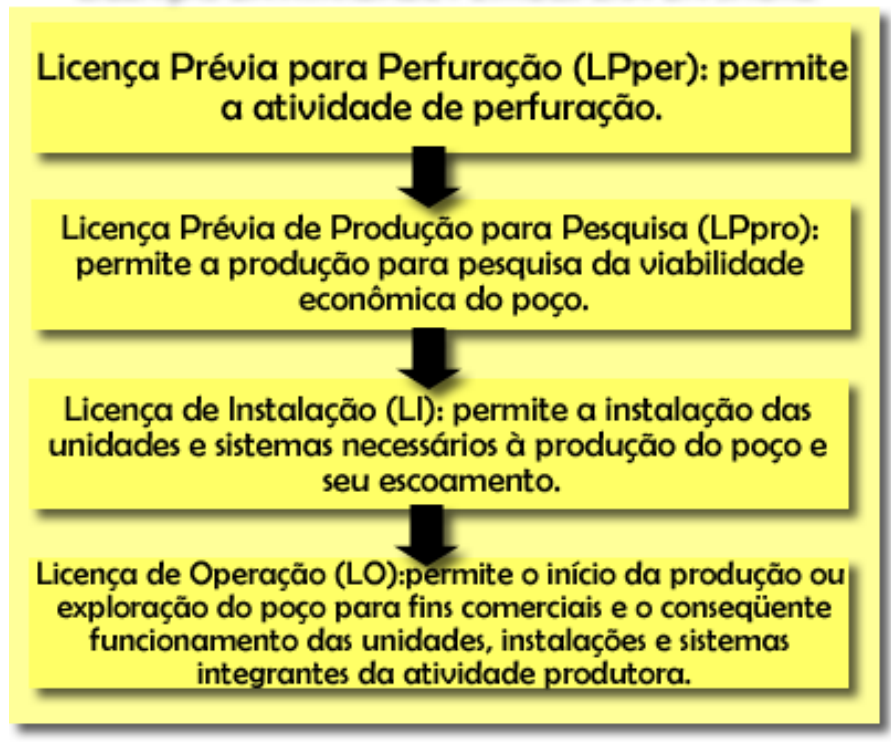

Figura 1 - Licenças da atividade on shore.

Fonte: SILVA et al. (2008), adaptado da Lei complementar 272/04 - RN.

No processo de licenciamento ambiental on shore, o órgão ambiental responsável, que no caso do nosso Estado é o IDEMA, utiliza-se de alguns estudos ambientais, como: Estudo de Impacto Ambiental (EIA) com o seu respectivo Relatório de Impacto Ambiental (RIMA), Relatório de Controle Ambiental (RCA), Estudo de Viabilidade Ambiental (EVA), Relatório de Avaliação Ambiental (RAA) e Projeto de Controle Ambiental (PCA).

\subsubsection{Estudo Ambiental}

Um estudo técnico que possui como intuito fornecer as informações e análises técnicas de uma atividade causadora de impactos ambientais, desde a localização, implantação, operacionalização e ampliação, para subsidiar o processo de licenciamento é considerado um estudo ambiental (SÁNCHEZ, 2006).

Já para a Resolução CONAMA 237/97, os estudos ambientais são todos e quaisquer estudos relativos aos aspectos ambientais relacionados à localização, instalação, operação e ampliação de uma atividade ou empreendimento, apresentado como subsídio para a análise da licença requerida, tais como: relatório ambiental, plano e projeto de controle ambiental, relatório ambiental preliminar, diagnóstico ambiental, plano de manejo, plano de recuperação de área degradada e análise preliminar de risco (CONAMA, 1997).

\subsection{IMPACTO AMBIENTAL}

O impacto ambiental pode ser definido, segundo Sánchez (2006, p. 462), como “a alteração da qualidade ambiental que resulta da modificação de processos naturais ou sociais provocada por ação humana".

Considera-se impacto ambiental, segundo a Resolução CONAMA 1/86, qualquer alteração das propriedades físicas, químicas e biológicas do meio ambiente, causada por qualquer forma de matéria ou energia resultante das atividades humanas que, direta ou indiretamente, afetam: 
I. a saúde, a segurança e o bem-estar da população;

II. as atividades sociais e econômicas;

III. a biota;

IV. as condições estéticas e sanitárias do meio ambiente;

$\mathrm{V}$. a qualidade dos recursos ambientais.

Entende-se por impacto ambiental, de acordo com a NBR ISO 14001:2004, qualquer conseqüência, negativa ou positiva, que resulte ou que possa resultar da interação dos aspectos ambientais ou elementos de processo, operações, serviços e produtos de uma organização com o meio ambiente durante as atividades do empreendimento.

\section{METODOLOGIA}

A estratégia para alcançar as metas relacionadas com este estudo passa pela pesquisa bibliográfica, com leitura e discussão de textos centrais à questão e legislações pertinentes, e a revisão crítica de documentos e publicações da área, a fim de fundamentar o tom do debate e as questões levantadas. Foram feitas leituras de estudos que analisaram a qualidade formal e de conteúdo de estudos ambientais, assim como do TR do IDEMA para a atividade de sísmica.

Como a análise técnica de um estudo de impacto ambiental não é de interesse exclusivo do agente decisório, e sim de todos, este trabalho se propõe a analisar um Relatório de Controle Ambiental (RCA) com o intuito de verificar se a prática existente retrata os conceitos teóricos. Portanto, o trabalho fará uma comparação dos itens exigidos no Termo de Referência do IDEMA com os que foram trabalhados no RCA, assim como foi feita uma pesquisa para a identificação da existência de boas práticas.

No que tange as boas práticas, destaca-se o estudo realizado pelo MPF que foi tomado como a principal referencia nesse aspecto. O mesmo retrata de maneira muito rica a temática a ser desenvolvida nesse trabalho.

A metodologia utilizada foi um estudo de caso de um RCA utilizado para a atividade de sísmica. Dessa forma, foi feita uma comparação dos itens exigidos no Termo de Referência do IDEMA com um Relatório de Controle Ambiental usado num processo de licenciamento ambiental pelo mesmo órgão, ou seja, foi visto se todos os itens exigidos legalmente foram contemplados no RCA e se os mesmo estão em conformidade. Esta técnica de estudo de impacto ambiental baseado dentro de um contexto legal que estabelece requisitos a serem observados e procedimentos a serem cumpridos, é conhecida como análise formal da qualidade de um estudo ambiental. Foi verificada, também, a repetição ou não das principais deficiências apontadas no elemento Mitigação e compensação de impactos, sendo trabalhado o conceito de qualidade de conteúdo, haja vista que o trabalho do MPF deve ser considerado uma referência.

\section{ESTUDO DE CASO}

O estudo foi iniciado fazendo-se a comparação dos pontos abordados no RCA de sísmica com os exigidos pelo Termo de Referência do IDEMA para a mesma atividade, em seguida, o Quadro 2 adiante, composto pelo elemento Mitigação e Compensação de Impactos e suas principais deficiências, foi utilizado como referência para análise do 
mesmo RCA. Observa-se que nesse estudo, os impactos previstos foram considerados a cada atividade do levantamento sísmico (Mobilização dos Recursos Materiais e Humanos, Abertura e Marcação de Picadas, Implantação de Pontos de Tiro, Detonação e Recuperação dos Pontos de Tiro) sendo cada atividade trabalhada nos meios físicos, bióticos e antrópicos, separadamente. Além disso, foi utilizada ferramentas de análise de impacto ambiental, sendo identificado impacto ambiental positivo. No entanto, quando se estuda a proposição de medidas mitigadoras, identificam-se pontos a serem melhorados no estudo.

Com relação ao Termo de Referência, constata-se que na matriz de Leopold ${ }^{1}$, disposta no capítulo cinco, os impacto ambientais são identificados e analisados segundo a componente do sistema ambiental e a fase de ocorrência, porém alguns merecem uma consideração no que diz respeito às conformidades exigidas no TR fornecido pelo IDEMA para a elaboração de um RCA referente à atividade de levantamento sísmico.

O estudo investigado não apresenta o detalhamento exigido no TR, na elaboração das medidas de mitigação. Exige-se o detalhamento dos processos, métodos, tecnologias e ações que permitam a prevenção, redução e/ou eliminação dos danos ambientais causados pelo empreendimento, ou ainda, a proposição de compensações ambientais que neutralizem os efeitos causados. Nem na matriz do capítulo cinco, nem as medidas propostas no capítulo seis apresentam de forma aprofundada os detalhes exigidos para a concessão da licença.

O estudo considerado não cita a natureza das medidas, se elas são preventivas ou corretivas, nem tampouco a eficiência dos equipamentos de controle de poluição, quanto aos padrões de emissão de efluentes líquidos, emissões atmosféricas e resíduos sólidos.

Outra conformidade legal exigidas é a classificação em relação à responsabilidade pela implementação, se seria o empreendedor, o poder público ou outrem e em relação ao custo total. Porém, no estudo nenhum desses aspectos são considerados, ficando a dúvida de quem deve implementar a medida e a viabilidade econômica da mesma.

A partir dessa etapa será elencado todas as medidas mitigadoras propostas, considerando cada meio individualmente, e será feita uma análise critica de uma por uma com o intuito de observarmos ou não as principais deficiências apontadas pelo estudo do MPF. Como veremos em nenhuma medida mitigadora proposta, foi feita a avaliação de sua eficiência, ou seja, o ponto ausência de avaliação da eficiência das medidas mitigadoras propostas não foi trabalhado.

\footnotetext{
1 A matriz de Leopold tem sido uma das mais utilizadas nos EIA/RIMA realizados no Brasil, sendo freqüentemente tomada como o método padrão para a elaboração desses estudos (IBAMA, 1985).
} 
Quadro 2 - Principais deficiências do elemento Mitigação e compensação de impactos.

\begin{tabular}{|l|l|}
\hline Mitigação e & Proposição de medidas que não são a solução para a mitigação do impacto; \\
compensação & Indicação de medidas mitigadoras pouco detalhadas; \\
& Indicação de obrigações ou impedimentos, técnicos e legais, como \\
& propostas de medidas mitigadoras; \\
& Ausência de avaliação da eficiência das medidas mitigadoras propostas; \\
& $\begin{array}{l}\text { Deslocamento compulsório de populações: propostas iniciais de } \\
\text { compensações de perdas baseadas em diagnósticos inadequados; }\end{array}$ \\
& $\begin{array}{l}\text { Não-incorporação de propostas dos grupos sociais afetados, na fase de } \\
\text { formulação do EIA; } \\
\text { Proposição de Unidade de Conservação da categoria de uso sustentável para } \\
\text { a aplicação dos recursos, em casos não previstos pela legislação. }\end{array}$ \\
\hline
\end{tabular}

Fonte: SÁNCHEZ (2006).

\subsection{MEDIDAS MITIGADORAS PARA O MEIO FÍSICO}

Como medidas mitigadoras preventivas (ver gráfico 1) quanto aos impactos negativos nesse meio, propõe-se:

1. Realizar a eventual umidificação das vias não asfaltadas utilizadas para acesso à área de modo a evitar a dispersão de poeira;

Não se observa nenhuma deficiência.

2. Realizar a regulagem periódica dos motores dos equipamentos (veículos, perfuratrizes, etc.) envolvidos no levantamento sísmico;

Não se observa nenhuma deficiência.

3. Apenas utilizar explosivos sismográficos licenciados pelo Exército Brasileiro;

Proposição de medidas que não são a solução para a mitigação do impacto, Indicação de obrigações ou impedimentos, técnicos e legais como propostas de medidas mitigadoras.

4. Armazenar os explosivos e detonantes com as devidas precauções de segurança, para evitar acidentes ou roubos;

Proposição de medidas que não são a solução para a mitigação do impacto, Indicação de obrigações ou impedimentos, técnicos e legais como propostas de medidas mitigadoras.

5. Restringir a manipulação dos explosivos estritamente ao pessoal capacitado;

Proposição de medidas que não são a solução para a mitigação do impacto, Indicação de obrigações ou impedimentos, técnicos e legais como propostas de medidas mitigadoras.

6. Manter um inventário diário detalhado dos explosivos utilizados, para evitar que sejam deixados no campo;

Proposição de medidas que não são a solução para a mitigação do impacto, Indicação de obrigações ou impedimentos, técnicos e legais como propostas de medidas mitigadoras.

7. Este item não foi contemplado no estudo analisado;

8. Manter uma distância de 100 metros do curso d'água sem promover corte na mata. Nesses locais, devem ser abertas picadas manualmente, sem corte de árvores, preservando a mata ciliar como barreira de proteção contra erosões e assoreamentos dos cursos d’água; Não se observa nenhuma deficiência. 
9. Não realizar picadas ao longo de margens de drenagens muito encaixadas com barrancos (caso existam), evitando represamentos em épocas chuvosas e mesmo erosão às circunvizinhanças;

Não se observa nenhuma deficiência.

10. Abrir apenas áreas estritamente necessárias ao trabalho, tais como, áreas para manobras e estacionamentos;

Não se observa nenhuma deficiência.

11. Não realizar picadas em encostas íngremes (caso existam). Proceder nesses locais a abertura manual, sem corte de árvores, evitando processos erosivos;

Não se observa nenhuma deficiência.

12. A abertura das linhas sísmicas deve ser dimensionada com a largura mínima necessária ao trabalho, sendo no máximo de 4 metros;

Indicação de obrigações ou impedimentos, técnicos e legais, como propostas de medidas mitigadoras.

13. Não furar, carregar e detonar nas margens de recursos hídricos superficiais (rios, lagos, represas), mantendo-se uma distância de segurança de no mínimo 30 metros, de acordo com cada caso;

Não se observa nenhuma deficiência.

14. Evitar furar, carregar e detonar em áreas alagadas;

Não se observa nenhuma deficiência.

15. Promover o imediato tamponamento dos buracos eventualmente gerados pelas detonações dos explosivos;

Não se observa nenhuma deficiência.

16. Os resíduos oriundos do acampamento-base (caso seja construído), e os gerados em campo, devem ser acondicionados em cestos específicos para cada tipo de material: 1 . Lixo orgânico, 2. Plásticos, Papéis, Metais e Vidros e; 3. Óleos e graxas. Os resíduos orgânicos devem ser encaminhados ao vazadouro municipal, os inorgânicos à usina de reciclagem mais próxima e óleos e graxas para empresas licenciadas e capacitadas para dar destinação final a esses resíduos;

Não se observa nenhuma deficiência.

17. Em caso de vazamento acidental dispor de recipiente capaz de acumular com folga todo o óleo/combustível armazenado nas máquinas utilizadas evitando a contaminação do solo;

Indicação de medidas mitigadoras pouco detalhadas. 


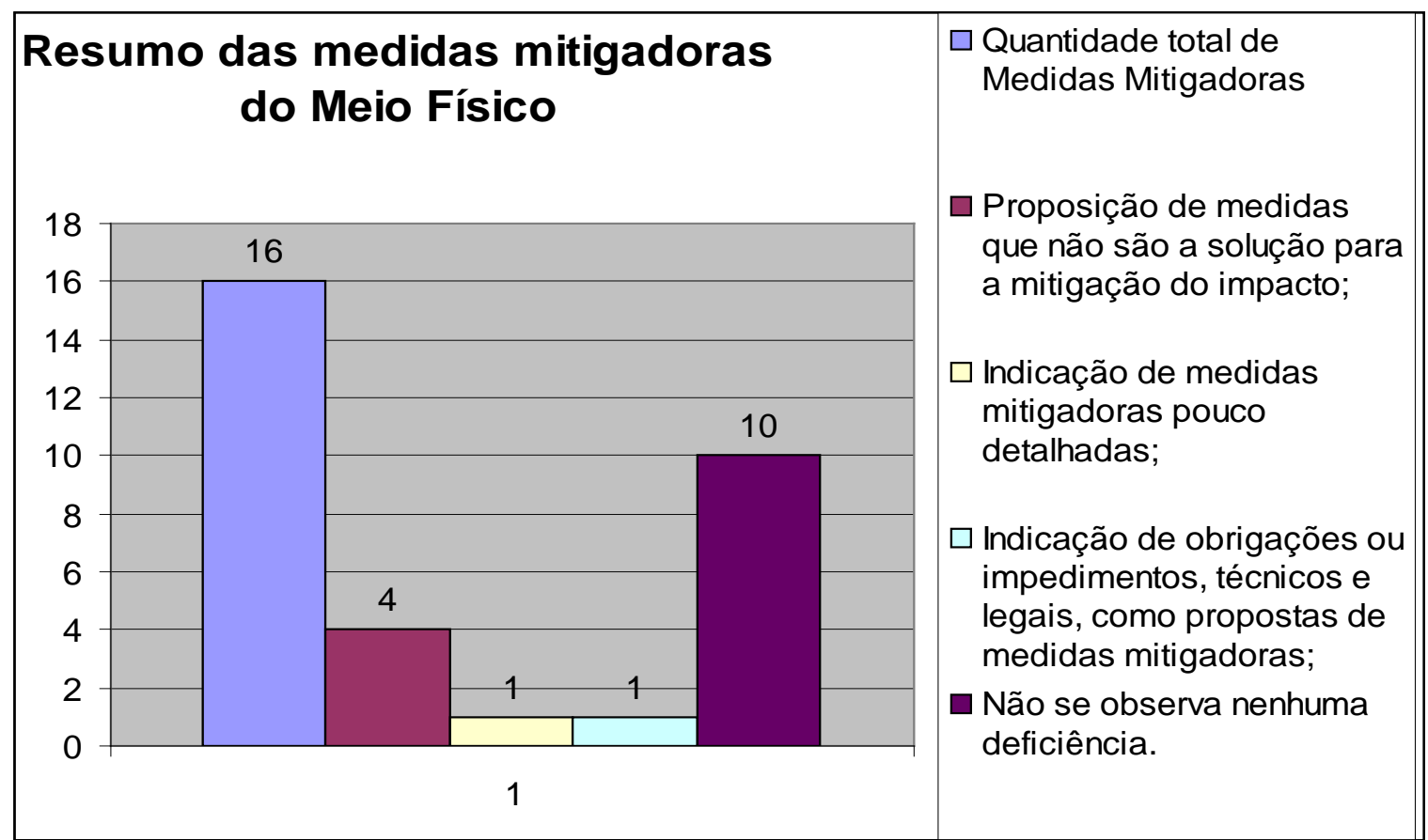

Gráfico 1 - Resumo das medidas mitigadoras do meio físico. Fonte: De acordo com a análise das medidas mitigadoras.

\subsection{MEDIDAS MITIGADORAS PARA O MEIO BIÓTICO}

Os procedimentos para minimizar os impactos ambientais para o meio biótico (ver gráfico 2) são:

1. Diminuição da Faixa de Remoção da Vegetação. Essa é limitada ao máximo de 4,0 metros para o caso de abertura manual das picadas, a largura será inferior a 1,5m;

Não se observa nenhuma deficiência.

2. Não remover árvores consideradas nobres e/ou frutíferas, tais como: angico, umburana, juazeiro, oiticica, imburana, quixabeira, carnaubeira, cajueiro e outras;

Não se observa nenhuma deficiência.

3. Não cortar árvores de grande porte, ou seja, tronco de diâmetro, à altura do peito, igual ou maior a 15 centímetros;

Não se observa nenhuma deficiência.

4. Recolhimento dos materiais utilizados. Todo o material é recolhido após as operações, preservando as condições encontradas antes dos trabalhos;

Não se observa nenhuma deficiência.

5. Não realizar aberturas em encostas íngremes. Nesses locais, recomendasse abrir picadas manualmente, sem corte de árvores, evitando processos erosivos;

Não se observa nenhuma deficiência.

6. Não abrir em margens de drenagens muito encaixadas com barrancos, evitando represamentos em épocas chuvosas e mesmo erosão nas áreas circunvizinhas;

Não se observa nenhuma deficiência. 
7. Não abrir áreas, além das estritamente necessárias ao trabalho, tais como, áreas para manobras e estacionamentos;

Repetição da recomendação do item 10 do meio físico. Proposição de medidas que não são é a solução para a mitigação do impacto.

8. Evitar raspar o solo orgânico e formar amontoados de terras ao longo das linhas sísmicas. Na medida do possível utilizar o trator de esteira com a lâmina afastada do solo apenas para tombar a vegetação sem a retirada da camada orgânica do solo. Isto facilitará a recomposição vegetal e microbiana mais rapidamente, evitando deixar o solo exposto aos processos erosivos por longo tempo;

Não se observa nenhuma deficiência.

9. Evitar o corte de vegetações que constituam abrigos de animais silvestres (ninhos, cortiços, tocas, etc.);

Não se observa nenhuma deficiência.

10. Nas margens de estradas, fechadas por vegetação, por onde cruzar uma linha sísmica deverá ser construída uma cerca (falsa cerca), ao término dos trabalhos de Levantamento Sísmico, com o objetivo de evitar a utilização da linha sísmica como via de acesso para caçadores, carros, carroças, etc.;

Não se observa nenhuma deficiência.

11. Os amontoados de vegetação que, porventura forem deixados pela abertura das linhas com trator de esteira, deverão ser espalhados ao longo da linha sísmica;

Não se observa nenhuma deficiência.

12. Limitar a limpeza do terreno e as obras somente a área física do empreendimento a ser implantado como forma de redução de locais geradores de ruídos; quanto mais próximos à atividade geradora destes ambientes, maiores são os impactos;

Deveria está no meio físico, fator ruído, Indicação de medidas mitigadoras pouco detalhadas.

13. Tanto a abertura das linhas sísmicas quanto as detonações devem ser atividades de curta duração como forma de evitar prolongar as fontes de ruídos (máquinas, equipamentos e explosivos), restabelecendo o mais rápido o ambiente natural;

Não se observa nenhuma deficiência.

14. Evitar o corte de vegetações que constituam abrigos de animais silvestres (ninhos, cortiços, tocas, etc.);

Não se observa nenhuma deficiência.

15. Resgate e transferência da fauna criticamente exposta às atividades para áreas isentas das operações;

Não se observa nenhuma deficiência.

16. Sinalização de trânsito e orientação dos operários nas estradas que dão acesso às obras como forma de prudência e redução de velocidade evitando acidentes com animais que estejam transitando pela área; 
Não trabalha o meio biótico, Proposição de medidas que não são a solução para a mitigação do impacto e Indicação de medidas mitigadoras pouco detalhadas.

17. Desenvolver ações de educação ambiental e divulgação de métodos de identificação de animais peçonhentos e de prevenção de acidentes com ofídios;

Proposição de medidas que não são a solução para a mitigação do impacto e Indicação de medidas mitigadoras pouco detalhadas.

16. Não será permitida a caça, comercialização, aprisionamento, destruição de ninhos, coleta de ovos e maus tratos a animais silvestres, pelos membros da equipe sísmica. Cabe a empresa exercer forte fiscalização sobre seu Quadro funcional ${ }^{2}$;

Indicação de obrigações ou impedimentos, técnicos e legais, como propostas de medidas mitigadoras.

18. Quando oportuno, aplicar um programa de educação ambiental, incentivando a população circunvizinha a preservação da fauna;

Indicação de medidas mitigadoras pouco detalhadas.

19. Mediante constatação de prática ilegal, comunicar ao IDEMA a fim de que sejam tomadas as devidas providências;

Indicação de medidas mitigadoras pouco detalhadas e Indicação de obrigações ou impedimentos, técnicos e legais, como propostas de medidas mitigadoras.

20. Evitar o corte de vegetação que constituem abrigos de animais silvestres (ninhos, tocas, etc);

Repetição da medida 14.

21. Diminuição da Faixa de Remoção da Vegetação. Essa é limitada ao máximo de 4,0 metros;

Não se observa nenhuma deficiência.

22. Limitar a limpeza do terreno e as obras somente a área física do empreendimento a ser implantado como forma de redução de locais geradores de ruídos; quanto mais próximos à atividade geradora destes ambientes, maiores são os impactos;

Repetição da medida 12.

23. Tanto a abertura das linhas sísmicas quanto as detonações devem ser atividades de curta duração como forma de evitar prolongar as fontes de ruídos (máquinas, equipamentos e explosivos), restabelecendo o mais rápido o ambiente natural;

Repetição da medida 13.

24. Realizar campanhas de conscientização sobre o assunto com trabalhadores das obras e moradores da região;

Proposição de medidas que não é a solução para a mitigação do impacto e Indicação de medidas mitigadoras pouco detalhadas.

25. Verificar os estoques de soro antiofídico nos postos de saúde e hospitais da região; Proposição de medidas que não é a solução para a mitigação do impacto e Indicação de medidas mitigadoras pouco detalhadas.

\footnotetext{
2 Esta seqüência numérica está de acordo com o estudo original analisado.
} 


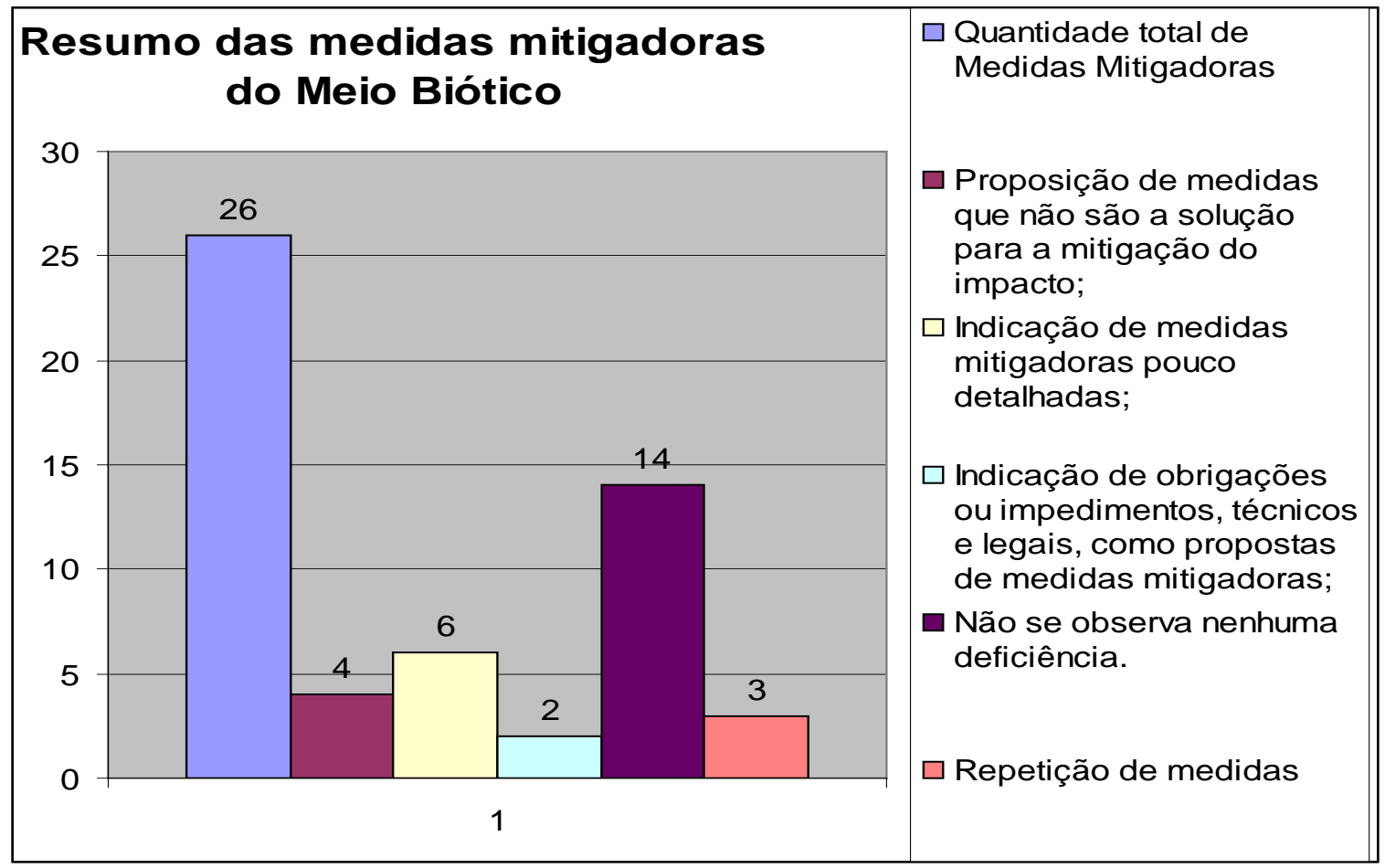

Gráfico 2 - Resumo das medidas mitigadoras do meio biótico. Fonte: De acordo com a análise das medidas mitigadoras.

\subsection{MEDIDAS MITIGADORAS PARA O MEIO ANTRÓPICO}

São propostas as seguintes medidas mitigadoras para meio antrópico (ver gráfico 3) relativas à implantação do Empreendimento:

1. Isolamento das linhas sísmicas quando estas cruzarem margem de estradas, para evitar que as mesmas se tornem acesso para os moradores do entorno do projeto;

Não se observa nenhuma deficiência.

2.Utilizar o mínimo de carga de explosivos necessários ao levantamento sísmico, bem como reuniões com pessoal residente próximo à área para esclarecimento sobre o projeto;

Não se observa nenhuma deficiência.

3.Realizar reuniões para esclarecimento às pessoas residentes próximas ao Empreendimento, quanto ao acesso à área do mesmo;

Semelhante a medida 2.

4. Destinação adequada para acondicionamento do material retirado;

Não relacionada ao meio antrópico. Proposição de medidas que não é a solução para a mitigação do impacto. Indicação de medidas mitigadoras pouco detalhadas.

5. Desenvolver plano de ação para evitar possíveis alterações ambientais dessa natureza; Não relacionada ao meio antrópico. Indicação de obrigações ou impedimentos, técnicos e legais como propostas de medidas mitigadoras. 
6. Destinação adequada para os resíduos gerados durante o processo de Levantamento Sísmico;

Indicação de medidas mitigadoras pouco detalhadas.

7. Utilização de equipamentos de proteção individual (EPI’s);

Indicação de obrigações ou impedimentos, técnicos e legais como propostas de medidas mitigadoras.

8. Indenização da safra agrícola;

Não se observa nenhuma deficiência.

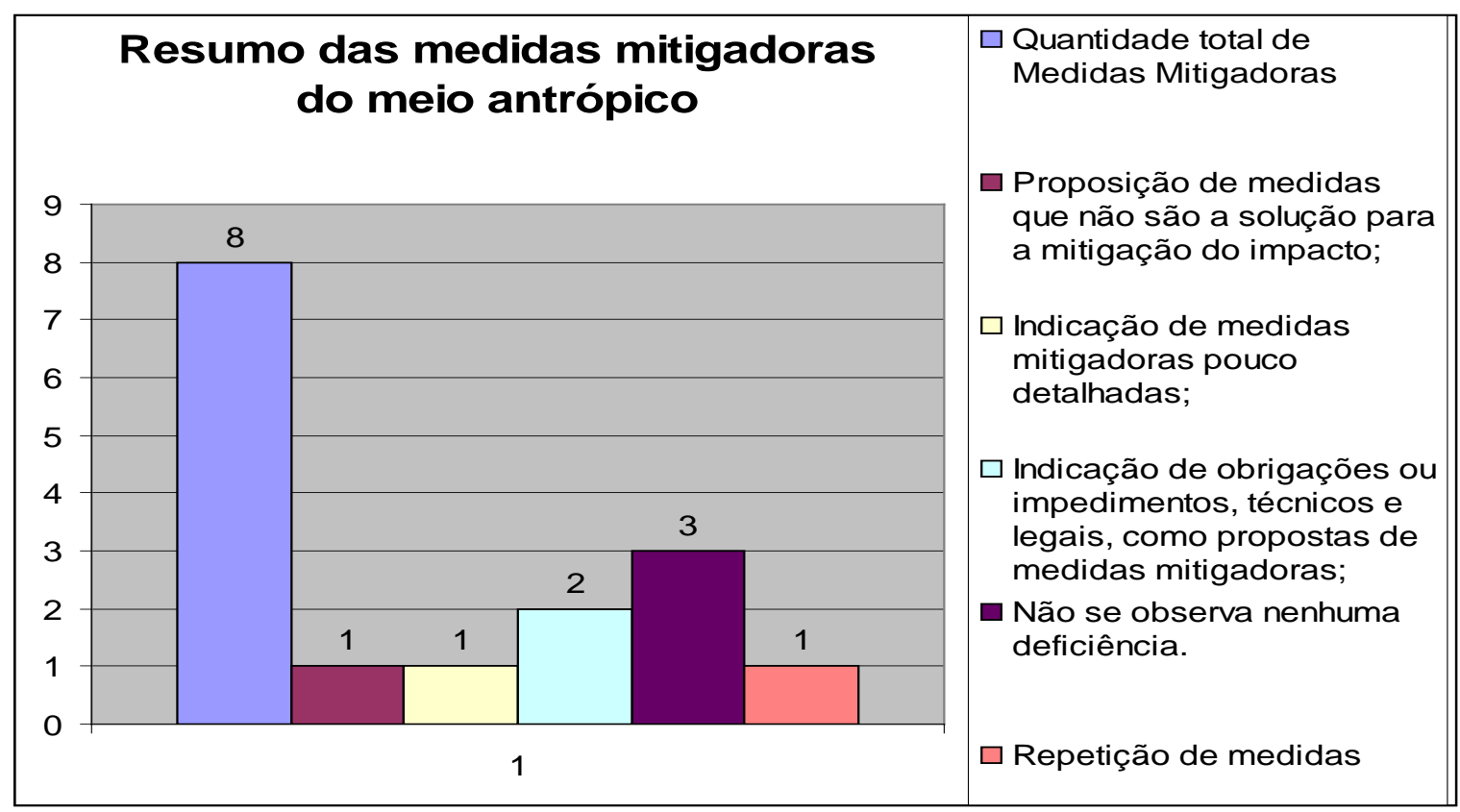

Gráfico 3 - Resumo das medidas mitigadoras do meio antrópico. Fonte: De acordo com a análise das medidas mitigadoras.

\section{CONSIDERAÇÕES FINAIS}

O RCA apresenta como pontos positivos o detalhamento das medidas mitigadoras a cada fase, sendo cada uma trabalhada nos diversos meios (físico, biótico e antrópico), separadamente, assim como foi utilizada ferramenta de analise de impacto ambiental indicada pelo IBAMA, tal como a matriz de Leopold.

Conforme se observa no estudo de caso, o RCA utilizado para a obtenção da concessão de licença ambiental da atividade de sísmica, não contemplou todos os itens legais exigidos no Termo de Referência do IDEMA, não apresentando o detalhamento exigido no TR, na elaboração das medidas de mitigação, não cita a natureza das medidas, se elas são preventivas ou corretivas, nem tampouco a eficiência dos equipamentos de controle de poluição, quanto aos padrões de emissão de efluentes líquidos, emissões atmosféricas e resíduos sólidos, além de não definir a responsabilidade de quem deve implementar a medida e a viabilidade econômica da mesma. 
Nessa situação, é oportuno o detalhamento das medidas de mitigação, caracterizando a sua natureza em preventiva ou corretiva, descrever a eficiência dos equipamentos de controle de poluição, definindo as responsabilidades e a relação custo/beneficio.

Acrescentando-se ao que foi mencionado, o RCA em estudo, apresentou as deficiências apontadas pelo MPF, ou seja, foram indicadas medidas que não mitiga o impacto, as medidas trabalhadas foram pouco detalhadas, foram utilizadas obrigações legais como medida mitigadora além erros na enumeração das medidas.

Nesse caso, é cabível a utilização de medidas que de fato mitiguem o impacto, as medidas devem ser detalhadas e não se devem utilizar obrigações legais como medida mitigadora, fato que ocorreu na indicação de utilização de EPI, por exemplo.

Desse modo, o RCA não garante ao analista, o atendimento aos requisitos mínimos estabelecidos pela regulamentação aplicável, assim como, não apresenta qualidade técnica suficiente para subsidiar a tomada de decisão sobre o empreendimento sendo necessárias as correções para que o mesmo possa ser melhor apreciado pelo órgão ambiental competente.

Assim, acreditamos que este trabalho desperta a consciência daqueles que se interessam pelas questões ligadas ao processo de obtenção de licença ambiental e proporciona uma leitura interessante aos profissionais que lidam com esse tema.

\section{REFERÊNCIAS}

1. ASSOCIAÇÃO BRASILEIRA DE NORMAS TÉCNICAS. NBR 13030: Elaboração e apresentação de projeto de reabilitação de áreas degradadas pela mineração. Rio de Janeiro, 1999.

2. _ NBR ISO 14001:2004. Sistemas de gestão ambiental: requisitos com orientações para uso. Rio de Janeiro, 2004.

3. BARBIERI, José Carlos. Gestão ambiental empresarial: conceitos, modelos e instrumentos - 2. ed. atual e ampliada - São Paulo: Saraiva, 2007.

4. BRANCO, Samuel Murgel. O meio ambiente em debate - São Paulo: Moderna, 1988 - (Coleção polemica)

5. BRASIL. Constituição (1988). Constituição da República Federativa do Brasil. Brasília, DF: Senado, 1988.

6. BRASIL. Congresso Nacional. Lei $\mathrm{N}^{0}$ 6938, de 31 de Agosto de 1981.Dispõe sobre a Política Nacional do Meio Ambiente, seus fins e mecanismos de formulação e aplicação, e dá outras providências. Diário Oficial da União, Poder Executivo, Brasília, DF, 02 de Setembro de 1981. P. 16509

7. CONSELHO NACIONAL DO MEIO AMBIENTE. Resolução 237. Brasil: CONAMA, 1997. 
8. FINK, Roberto Daniel; ALONSO, Hamilton Jr.; DAWALIBI, Marcelo. Aspectos jurídicos do licenciamento ambiental. Rio de Janeiro: Forense Universitária, 2004.

9. LIMA, Maíra Luísa Milani de. Licenciamento ambiental e Gestão de Riscos: o caso da usina hidrelétrica de barra grande (RS). 2006. Dissertação (Mestrado em Direito) - Centro de Pós-Graduação em Direito, Universidade Federal de Santa Catarina, Florianópolis, 2006.

10. PHILIPPI Jr. A, Pelicioni MCF, editores. Educação ambiental e sustentabilidade Barueri, São Paulo: Manole, 2005 - (Coleção Ambiental; 3).

11. POLÍTICA ESTADUAL DE MEIO AMBIENTE DO ESTADO DO RIO GRANDE DO NORTE (PEMA). Lei complementar $n^{0}$ 272, de 03 de março de 2004. Disponível em: http://www.rn.gov.br/secretarias/idema/legislacao.asp >. Acesso em 03 de jun. de 2009.

12. SÁNCHEZ, Luiz Henrique. Avaliação de impacto ambiental: conceitos e métodos São Paulo: Oficina de Textos, 2006.

13. SILVA, Robson Garcia da; PEGADO, Erika Araújo da Cunha; SILVA, Valdenildo Pedro da. A exploração e produção on shore e o licenciamento ambiental no Rio Grande do Norte. In: V CONGRESSO DE INICIAÇÃO CIENTÍFICA, 2008, Natal. Anais... Natal: CEFET-RN, 2008. Disponível em: $<$ http://www.ifrn.edu.br/secoes/pesquisa/arquivos/anais-congic2008.pdf/view?searchterm=congic $>$ Acesso em: 03 de jun. 2009. 